\title{
Does the teaching performance of faculty in physiology change over the years?
}

\author{
Mehnaaz Sameera Arifuddin, Farah Bahmed, M. Anthony David, Mohammed Abdul Hannan \\ Hazari
}

Department of Physiology, Deccan College of Medical Sciences, Kanchanbagh (PO), Hyderabad-500058, Andhra Pradesh, India.

$\begin{array}{ll}\text { ARTICLE INFO } \\ \text { Received } & : 23 / 04 / 2013 \\ \text { Accepted } & : 18 / 08 / 2013 \\ \text { Published } & : 09 / 03 / 2014\end{array}$

\section{KEYWORD}

Physiology

Teaching skills

Student feedback

\section{ABSTRACT}

Introduction: Much of the foundation of knowledge in medical science is provided by human physiology. It was the critical thinking of various great people who provided meaningful contributions to the field of physiology. A right approach to understand physiological concepts is the stepping stone to a flourishing medical career. Therefore, it becomes imperative on the part of a teacher to impart the right perceptions of physiology to medical students. Students, being end-users, can evaluate the teaching skills of a teacher so that the latter can adapt and improve themselves. Objective: This study was designed to analyze the performance of 3 faculty members of the department of physiology and to document any change in their teaching techniques over the study period of 5 years. Method: The teaching performance of three faculty members of department of Physiology was evaluated by first year MBBS undergraduates over a period of 5 years through a feedback form. These three faculty members had an average of twenty years of experience in teaching. The feedback forms were collected and analyzed using appropriate statistical methods. Result: There was a significant decrease in performance over the years in all the three faculty members, though it did not follow any regular trend. Conclusion: There is a non-linear decreasing trend in the teaching performance of the 3 faculty members as assessed by the student feedback.

(c) Medical Education Department, School of Medical Sciences, Universiti Sains Malaysia. All rights reserved.

CORRESPONDING AUTHOR: Dr. M. Anthony David Swaroop Kumar, Department of Physiology, Deccan College of Medical Sciences, DMRL 'X' Road, Kanchanbagh (PO), Hyderabad-500058, Andhra Pradesh, India. Email: antdavsku@gmail.com

\section{Introduction}

Medical education aims to improve health care of the population. The onus of it lies with the medical practitioners who gain proper knowledge and expertise in medical institutions. It's a common practice to evaluate a medical student's proficiency via regular conduction of examinations and viva voce; and the final result reflects mainly on the student's performance itself with no consideration of the teaching methods practiced by the faculty. Though late, the importance of feedback in medical education has been understood by the medical fraternity and now measures are being taken to improve the overall development of medical students by taking into consideration the medical teachers' teaching skills while delivering a lecture. 
Medical institutions throughout the globe have implemented ways to evaluate the performance of their faculty members which is done mostly by medical students. This is made possible by providing feedback forms to students for evaluation of medical teachers. Thus, the active and direct involvement of students in evaluation helps to improve the overall standards of medical education because it serves to act as a tool for teachers to implement modifications, if necessary, in their teaching methods [1]. The performance of a faculty member in any institution is based on a number of factors including their qualifications, experience in teaching and research activities, level of commitment to their profession, inclination for self-improvement, etc. [2].

Human physiology, like other basic medical sciences, has to be taught in a conceptualized manner to be understood in its totality. The ability of a teacher to drive home the basic concepts reflects on his/her teaching skills. Physiology, an integrated science, advances our understanding of how various systems are controlled and regulated. The present curriculum however, allows for transfer of subjective information to students without any importance being given to its practical outcomes [3]. Most of the times it has been experienced by medical graduates of this institution that it has become quite difficult to integrate the clinical findings they come across in various patients with the underlying pathophysiology. There must be something amiss somewhere; one of the factors could be the lack of understanding of physics and chemistry for teaching physiology. Or it could be that it is being taught by inexperienced faculty. With the advent of newer technological teaching aids, senior faculty may find it difficult to get acquainted with the same. And though they may be good at their subject, integrating their teaching style with audio-visual aids may be an obstacle in delivering a lecture [4]. Physiology like any other branch of medicine is progressing and for the improvement in the undergraduate medical course, teaching and evaluation methods need to be modified at regular intervals [3].
Feedback is considered as an important aspect of teaching in any situation. Studies have shown that receiving feedback at regular intervals keeps the teachers hold on to their subject of interest and also paves a way for further improvement in delivering a lecture. It also helps them fine tune their communication skills [5].

Therefore this study aims to document any change in the teaching abilities of the physiology faculty members over a period of five years by analyzing the feedback given by students.

\section{Method}

The study was conducted in the department of Physiology, Deccan College of Medical Sciences between 2009 and 2013. The study group consisted of 3 faculty members of department of Physiology. Informed consent was taken from them and specific codes A, B and C were assigned to them for anonymity. Each batch of 150 first year MBBS (Bachelor of Medicine and Bachelor of Surgery) students were given a feedback form for evaluating teaching performance during theory lectures of these 3 faculty members at the end of the second semester of the academic year. The form was explained to the students before they started their evaluation. The quantitative feedback included grading of 5 characteristics of teaching methods adopted by the faculty members as excellent (grade 1), good (grade 2), average (grade 3), not bad (grade 4) and needs improvement (grade 5). The five teaching characteristics were creating interest; making students understand; use of audio/visual aids; class control; and student interaction. The feedback forms were collected and numbered randomly. The responses in each of the 5 areas were added and used for statistical analyses. Due to inter-personal differences that may arise when the five teaching characteristics are individually considered for each faculty, cumulative scoring was adopted to get an overall view of their teaching performance. A cumulative score of 5 represents best performance and a score of 25 represents poor performance. After analysis, the results of their individual feedback were provided to each of the three faculty members. This helped them to 
adapt as necessary and improve their teaching skills. The learning cycle of the faculty is shown in the figure 1.

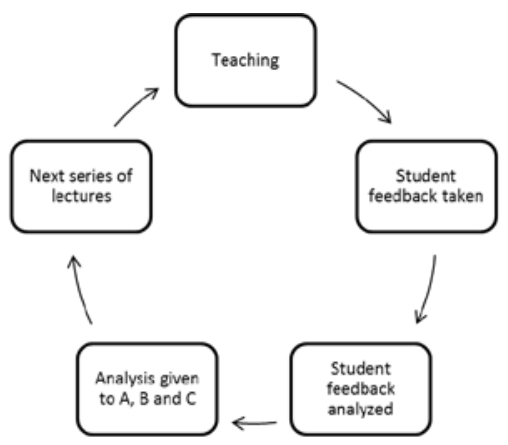

Figure 1: Learning cycle of the faculty

\section{Statistical analyses}

Statistical analyses were done using SPSS 17.0 (SPSS Inc., Chicago, USA). Repeated measures ANOVA was done to know the difference in teaching performance for each faculty member over the study period of 5 years. Statistical significance was set at $\mathrm{p}<0.05$ at $95 \%$ confidence intervals.

\section{Result}

Figure 2 shows the number of students in each batch who participated in the evaluation.

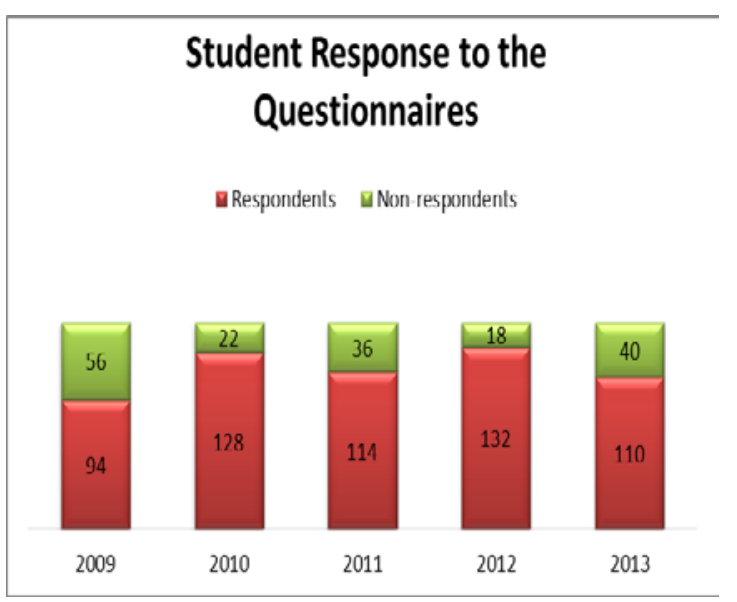

Figure 2: Student response to the questionnaires

Table 1 shows adjusted means of teaching performance of faculty A, B and C through 2009 to 2013.

Table 1: Adjusted mean score of teaching performance within subjects at different time interval

\begin{tabular}{|c|c|c|c|}
\hline \multirow{2}{*}{ Year } & Faculty A & Faculty B & Faculty C \\
\cline { 2 - 4 } & $\begin{array}{c}\text { Adjusted mean } \\
\text { (95\% CI; lower, upper) }\end{array}$ & $\begin{array}{c}\text { Adjusted mean } \\
\text { (95\% CI; lower, upper) }\end{array}$ & $\begin{array}{c}\text { Adjusted mean } \\
\text { (95\% CI; lower, upper) }\end{array}$ \\
\hline $\mathbf{2 0 0 9}$ & $8.66(8.06,9.26)$ & $7.31(6.80,7.82)$ & $11.98(11.06,12.91)$ \\
\hline $\mathbf{2 0 1 0}$ & $10.37(9.56,11.18)$ & $8.88(8.20,9.56)$ & $12.37(11.55,13.18)$ \\
\hline $\mathbf{2 0 1 1}$ & $9.40(8.69,10.12)$ & $7.59(7.00,8.16)$ & $11.83(11.12,12.54)$ \\
\hline $\mathbf{2 0 1 2}$ & $9.79(8.88,10.70)$ & $10.11(9.21,11.02)$ & $15.08(14.22,15.95)$ \\
\hline $\mathbf{2 0 1 3}$ & $12.63(11.66,13.59)$ & $9.69(8.83,10.54)$ & $16.43(15.50,17.35)$ \\
\hline
\end{tabular}

Table 2: Comparison of teaching performance score within subjects across 2009 to 2013

\begin{tabular}{|l|c|c|c|c|c|c|}
\hline \multirow{2}{*}{$\begin{array}{l}\text { Duration of } \\
\text { assessment }\end{array}$} & \multicolumn{2}{|c|}{ Faculty A } & \multicolumn{2}{c|}{ Faculty B } & \multicolumn{2}{c|}{ Faculty C } \\
\cline { 2 - 6 } & $\begin{array}{c}\text { Mean } \\
\text { difference }\end{array}$ & P-value* & $\begin{array}{c}\text { Mean } \\
\text { difference }\end{array}$ & P-value* & $\begin{array}{c}\text { Mean } \\
\text { difference }\end{array}$ & P-value* \\
\hline $\mathbf{2 0 0 9}-\mathbf{2 0 1 0}$ & -1.713 & 0.020 & -1.574 & 0.012 & -0.383 & 1.000 \\
\hline $\mathbf{2 0 1 0}-\mathbf{2 0 1 1}$ & 0.968 & 0.820 & 1.298 & 0.054 & 0.543 & 1.000 \\
\hline $\mathbf{2 0 1 1}-\mathbf{2 0 1 2}$ & -0.383 & 1.000 & -2.532 & 0.000 & -3.255 & 0.000 \\
\hline $\mathbf{2 0 1 2}-\mathbf{2 0 1 3}$ & -2.840 & 0.000 & 0.426 & 1.000 & -1.340 & 0.519 \\
\hline
\end{tabular}

* Repeated measures ANOVA, significant at $\mathrm{p}<0.013$ as significant at $95 \%$ CI 
A repeated measures ANOVA (with a HuynhFeldt correction if sphericity assumption is violated) determined that the estimated marginalized mean teaching performance statistically significantly differed over years for Faculty A $(\mathrm{F}(4,372)=14.066, \mathrm{p}<0.001)$; Faculty B $(\mathrm{F}(3.513,326.712)=11.315, \mathrm{p}<$ $0.001)$ and Faculty $C(F(4,372)=22.473, p<$ $0.001)$.
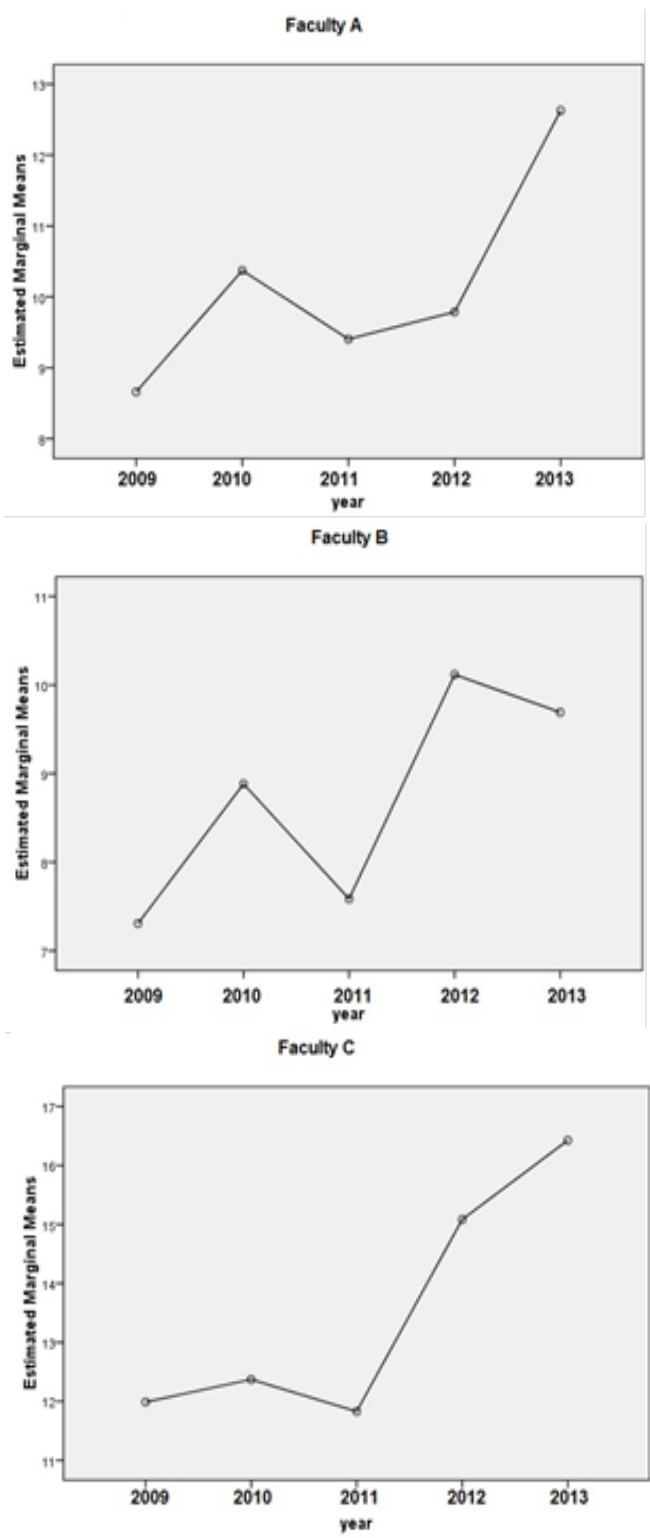

Figure 3: Estimated marginal means of faculty A, B and $\mathrm{C}$.

Table 2 presents mean differences between the teaching performance of the faculty members over consecutive years and their statistical significance on Post-hoc tests after Bonferroni correction. Figure 3 depicts visual impression of change in faculty performance through 20092013.

\section{Discussion}

There has been a recent emergence of problembased learning in the physiology curriculum which causes medical undergraduates to emphasize on the pathophysiology without giving importance to the normal function. What has been suggested by Penelope Hansen is that students should be exposed to patients in the primary care setup so that they can extrapolate the normal function from the deranged one in the patients. Hence, learning about normal function provides for one of the best foundations for learning about various disorders. Thus a teacher can incorporate clinical questions related to the topic in his/her lecture so that students can comprehend easily [6].

Apart from the above, evaluation and feedback of one's teaching methods provides a platform for the teachers to improve upon their teaching so that more students can be benefitted and can help students develop the required skills for a meaningful medical career. This needs the teachers to make improvements while delivering a lecture. They should be well aware of the students' level of knowledge. A lecture should begin with specification of learning objectives, providing structure and sequence of the topic. It is of prime importance to gain the attention of students as well as maintain a good rapport with them. However, the key teaching skill is to create an understanding of the subject among the students. This can be done by good preparation of the topic; appropriate use of audio-visual aids like the blackboard, power-point presentations; systematization of the concepts and phenomenon in a step-wise and clear manner; and summarizing the main and important points at the end of the lecture. Presentation of essential concepts without providing too much detail will help in maintaining the interest of students throughout the lecture. A teacher should be responsive to the students during the lecture also. All this enables him or her to have better class 
control. This positively makes for a better teaching-learning experience for the learners. This implies that student-teacher interaction is also necessary to deepen their understanding in the subject. It's via these measures that the theoretical knowledge if properly explained to students can form the framework for practical expertise which will be gained in the later part of their medical curriculum [7].

For the evaluation of teaching qualities, it is important to be familiar with the term 'good' teaching as it highly subjective. Recent studies have defined good teaching as a medium which enables student learning through a focus on conceptual understanding rather than didactic lectures. Good teaching makes learning a pleasurable experience. It creates a positive feeling in students; i.e. they develop interest in the subject which enables them to make appropriate use of their cognitive abilities to understand and question the facts presented to them. A good teacher should emphasize on the depth of learning rather than breadth of coverage; should unambiguously explain the structure of the subject; should build the lecture on what the students already know and challenge them so that their misconstructions are done away with; should be able to provoke a dynamic response from the students while teaching by questioning as well as inviting questions, rather than merely trying to expand their existing database [8].

This being a highly technological age, techsavvy students acquire information from different sources which is available to them through the internet. This may be the reason for the number of inattentive students during a lecture to be on the rise. However, this can be dealt effectively by the teacher only when he/she gets acquainted with the techniques by which a lecture can be made lively and interactive. This includes appropriate use of the blackboard, power-point presentations, interactive sessions, videos and animated graphics, etc. Our institution and the faculty have been in the past 5 years of study adopting newer methods of teaching as mentioned above. But the results have been unsatisfactory with respect to these 3 faculty members. The other reason for the decline in their teaching performance could be that they have not taken the student feedback results provided to them in a positive framework and have continued to teach without making any necessary modifications in their teaching styles. This could also be attributed to their increasing age which may have made them immune to any further improvements. Individual characteristics and a lack of motivation can also act as probable barriers against changing individual teaching behavior. Even though the average teaching experience is about 20 years, the decreasing trend seems to be independent of this factor. Physiology is not just a basic science, it is a health science, an experimental science; and unless its concepts are taught in a 'how, why, when, where and what' framework, medical undergraduates stand far from being benefitted in understanding the clinical subjects later.

\section{Conclusion}

This study shows that there has been a non-linear declining trend in the teaching performance of physiology faculty members which could be attributed to lack of initiative to improve, no effective interaction with students, inappropriate use of teaching methods. Giving feedback can itself be a learning experience for students. They can gain an insight into their role as learners [9]. Thus this process could be of double benefit helping the students as well as the faculty. Perhaps a study involving faculty with less of teaching experience would show a positive trend in their teaching performance.

Limitations of this study:

1. The total number of respondents in each batch who evaluated the teaching performance of the 3 faculty members is different.

2. The students are of different batches of entry into medical school, from 2009 to 2012.

3. Simultaneous peer review evaluation was not done.

\section{Reference}

1. Amr M, Al Saeed U, Shams T. Medical students' perceptions of teaching evaluation 
in psychiatry. Basic Research Journal of Education Research and Review 2012; 1(5):81-84.

2. Singh C, Gopal A, Mishra S. Extraction and analysis of faculty performance of management discipline from student feedback using clustering and association rule mining techniques. Electronics Computer Technology (ICECT), 2011 3rd International Conference on 8-10 April 2011; 4:94-96.

3. Dandannavar VS. Curriculum Development for Integrated Teaching (Module) - MBBS Phase I Students. Asian J Exp Biol Sci 2011; 2(3):474-481.

4. Tufts $M$ and Higgins-Opitz S. Medical physiology education in South Africa: what are the educator's perspectives. African Journal of Health Professions Education 2012; 4(1). [Available at http://www.ajhpe.org.za/index.php/ajhpe/arti cle/view/148/82, last accessed on May 19, 2013].
5. Hall M, Hanna LA, Quinn S. Pharmacy Students' Views of Faculty Feedback on Academic Performance. Am J Pharm Educ. 2012; 10; 76(1): 5.

6. Hansen P A. Physiology's recondite curriculum. Advan in Physiol Edu 2002; 26:139-145.

7. Brown $G$ and Manogue M. AMEE Medical Education guide no. 22: Refreshing lecturing: a guide for lectures. Medical Teacher 2001; 23(3):231-244.

8. Teaching according to how students learn In: Teaching for quality learning at university: What the student does, $3^{\text {rd }}$ edition, Biggs J and Tang C, pp: 24-25, Mc Graw Hill Society for Research into Higher Education and Open University Press.

9. La Lopa, J. Student reflection on quality teaching and how to assess it in higher education. Journal of Culinary Science \& Technology 2011, 9 (4), 282-292. 